Rita Spalva

\title{
Improvement of Dance Composition Skills During the Study Process in the Perspective of the Newest Motor Learning Models
}

DOI 10.1515/sigtem-2016-0017

\begin{abstract}
In today's dynamic world, where technologies have changed the understanding of time and space, the discussion about the body as a communicative performer in the new information field becomes a topic of interest. Different body techniques have become prevalent (sports, fitness, dance), which contribute to the scientific interest in the movement determination, inheritance, ergonomics and other aspects of movement quality. This article analyses recent motor learning models (Fitts, Posner, Gentile, etc) and substantiates the usefulness to introduce the three-stage learning model in any field related to motor skills. The article analyses the effectiveness of the proposed model in practice as part of the study course Dance Composition at the Riga Teacher Training and Educational Management Academy. The research results show that the ability to transfer acquired movement skills into new situations and to use them for performing independent creative tasks is a testimony to a high level of application, what is the goal of the introduction of the proposed model.
\end{abstract}

Keywords: dance composition, dance composition skills, motor learning models.

\section{Introduction}

Phenomenology, one of the most impressive fields of 20th century philosophy, has developed the philosophical tradition of the phenomenology of the body, which offers a new approach to the setting and solving of the body movement problematic. In its view, body activity and perception leads to the search for a new sense in the exploration of the movement (Мерло-Понти, 1999). Maurice Merlo-Ponty's philosophical milestone in the explanation of body movement and interaction has enabled many of today's scientists to focus on movement modelling in order to improve movement skills in various types of body activities, including dance. As a result, scientists have developed a diverse range of motor learning patterns that promote motor movement skills. These models are also applicable in dance education when they are used in the learning process for students' artistic advancement.

\section{Aim of the Study}

The aim of the research is to analyse the effectiveness of the Fitts/Posner three-stage learning model in the study process of dance composition.

*Corresponding author: Rita Spalva, Riga Teacher Training and Educational Management Academy, Latvia,

E-mail: rita.spalva@rpiva.lv 


\section{Materials and Methods}

The theoretical method applied in this research is the analysis of various motor models and the empirical method, i.e. a pedagogical observation and teaching experience analysis.

Although interest in the research of human movement specifics in society has been present for more than 100 years, Jack Adams is considered to be the pioneer of the modern human movement theory. In 1970, he was the first to theoretically solve the problem of the purposefulness of movement. Along with the rapid development of sports and professionalisation, movement accuracy and ergonomics became important research topics.

Adams believed that by repeating movements several times, it becomes possible to adjust and to approximate them towards their ideal form to the maximum. The practical activity is a way to make the movement become maximally identical to the ideal matrix. The theory of Adams consists of two basic elements: memory (memory trace) and perception (perceptual trace). According to Adams, repetition and simultaneous preservation of a movement in memory is an important condition for its correction (Adams, 1984).

Based on these findings, the psychologist Antoinette Gentile elaborates a two-level learning model, which consists of (1) an initial stage and (2) later stages. The initial level of Gentile's model emphasises on proper placement and mutual coordination of the movement (movement coordination patterns), which in the case of dance learning is associated with the skill to deploy dance movements in time and space. Within the second, the later, stage, Gentile raises more complex operation principles - adaptability, consistency and efficiency - and she emphasises efficiency of students' independent activity in the training stage (Edwards, 2011).

In 1967, American psychologists Paul Fitts and Michael Posner presented to the public the developed three-stage learning model, which was successfully applicable in any motion acquisition process. Its content refers to three interrelated levels of learning: (1) cognitive, (2) associative and (3) autonomous (see Figure 1). The transition from level to level is associated with skill strengthening, continuity and control, which can be achieved within the study process through various teaching techniques and an individual approach (Fitts, Posner, 1967).

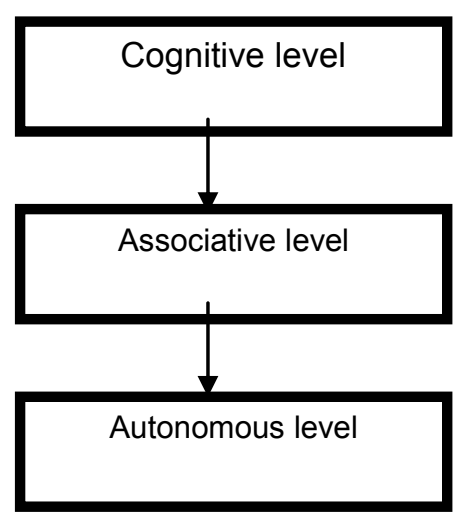

Figure 1. Three-level learning model

The first stage of the Fitts/Posner model is related to the type of learning when a beginner focuses on a cognitively oriented problem. This is the time when a student tries to answer questions like "What is the aim of this action? How can I achieve it? What are the means to an end?" During this phase, students create new concepts of movement and form new motor skills. Fitts and Posner recommend clarifying the need of the cognitive activity to the student as well as to develop closer cooperation between the teacher and students to provide process feedback.

On the cognitive level, the student learns to understand the nature of the subject, develops new strategies for solving tasks, and learns to determine their usefulness. The study results during the first 
stage tend to be variable with many already foreseeable inaccuracies and possible improvements to make. These are the situations when the student understands that a mistake was made, but still does not know how to correct it. However, at the same time, the student begins to evaluate options and develops selective attention required for new tasks. The main task on the cognitive level is to teach how to do something. It is therefore important to use such methods such as filming the created movements followed by an analysis in order to develop an understanding of the proper placement of movements as well as the use of force in performances.

Fitts and Posner call the second learning phase the associative phase. In the view of Richard Magill, the transition from the previous (cognitive) level to the associative one occurs sequentially, based on the experience gained in the previous stage and it ensures the use of already existing knowledge and skills (Magill, 2007). In the associative stage, the movement in space and time becomes more purposefully organised. Students are able to enrich the movement - they diversify and develop it and they can improvise within the limits of the proposed material. Errors in the movement design are less frequent, and they are not as pronounced, because students have learned to identify them independently. In this stage, the teacher becomes a mentor for maintaining a dialogue between students and the teacher is the best method to improve movement in this learning phase.

In the third, autonomous level, certain movement skills become almost automatic, and students are able to easily perform them. Students have many more opportunities to create new movements. In this stage, students can achieve a high artistic level because of the ability to control the performed tasks independently. In the autonomous stage, students make wide use of a diverse range of movement creation techniques and are able to carry them out independently, not only the staged movements, but also the analysis and the self-assessment of their practices. At this stage, a teacher focuses on the analysis of student performance and encourages an understanding of the effectiveness of each performance. In the third learning stage, the teacher must be able to organise the work so that the highest-level skills grow and develop through an interaction between theoretical knowledge and practical experience.

The Fitts/Posner model is widely used in sports and dance pedagogy, as well as interdisciplinary sciences. Mechanical movement learning is replaced with a comprehension of cognitive activation and determination throughout the process of movement learning. This approach ensures correct acquisition of movement techniques in the shortest possible time in order to be able to make further progress in the future.

Dance composition is '...the art of making dances, the gathering and organization of movement into order and pattern' (Encyclopedia Britannica). Composition as the art of creating a dance combines the author's emotional impulses for artistic practice with the choice of various methods to create a perceptible and effective dance image (Spalva, 2004). Peculiarities of the Dance Composition course manifest in the condition that it is based on students' prior knowledge in one of the dance techniques (folk dance, modern dance, sports dance, etc) and students' somatic skills. Dance Composition subject can be successfully acquired only by those students who have gained previous experience in certain dance techniques, which becomes the raw material for composition in the study process. Knowledge in one of the dance techniques is crucial to create and stage the composition when the author demonstrates composed movements and their connections to the performers (Spalva, 2014).

\section{Results}

The study course 'Dance and Rhythmic Teacher' plays an important role within the Riga Teacher Training and Educational Management Academy's professional bachelor's programme - it is given 12 credits (18 ECTS) and the classes continue for four semesters. Development process of the course contents took into account the fact that students have different backgrounds and knowledge both from the point of view of dance genres as well as the technical feasibility of dance performance. Teacher experience in practice and theory of dance composition allowed developing a purposefully organised study course, the main focus of which was the development of different levels of somatic skills and each individual's interests. It is important that the teacher is able to evaluate not only the level of each student individually, but also to model each 
student's potential opportunities. Therefore, in the first semester, which corresponds to the cognitive level of the model, the emphasis is on learning and strengthening of the simplest dance composition elements; these are improvisational skills, motion design and connection of elementary movements. On the cognitive level, the teacher draws great attention to the understanding of music within the dance staging process, so a substantial proportion of the scheduled time is devoted to strengthening the knowledge of the musical rhythmic structure, the form and contents of music.

Students apply the acquired knowledge and skills to create a completed composition - in the course of the semester, students are asked to create two independently performed works: (1) a dance composition, where the performers are children aged 5 to 7 (pre-school age); (2) a dance composition, where the performers are adults, and the target audience - children of different ages. When creating these compositions, students must also comply with the legalities of composition such as perceptibility, musicality, development and reaching the target audience.

At the cognitive level, as students create the very first dances in their experience, they primarily use fixed movements, i.e. those that are already firmly established in their memory from the past experience of acquiring dance techniques. Consequently, the teacher must take into account that the result will be rather expected - the means of expression are already established and approbated in different dance genres.

To build the student understanding of the advantages of new, unexpected solutions, it is important that teachers demonstrate works of recognised experts, using materials - DVDs as well as their own videos of the first creative exercises - to stimulate imagination. To foster student interest at the cognitive level, it is important to draw them in by demonstrating the work of leading choreographers, using online resources or videos.

An example of interesting analysis is the staging $L^{`}$ enfant et les sortile 'ges at the Netherlands Dance Theatre (choreography by Jiř́ Kylián, music by Maurice Ravel's), which is also available on DVD at the library resources of RTTEMA. Attention is paid to the staging's unusual form solution to address the audience of children - a moving (dancing) scenery, personification of objects, choice of movement for image formation and other staging qualities.

A strong stimulus to maintain the interest in the Dance Composition study course is each student's progress analysis that the teacher performs after each student's creative task. New types of co-operation skills are formed, as the students become dance performers in the creative exercises of their classmates. This creates an additional opportunity to analyse each staged dance from an artist's position.

The creative tasks performed in the second and third semesters of the Dance Composition course correspond to the second, associative learning model level. With the growing experience, students begin to understand unlimited possibilities of variativity - they understand movement composition diversity by using techniques such as repetition, confrontation of unison and canon, as well as an infinite number of possibilities provided by the motion arrangement in space. At this level, the main emphasis is placed on the placement of movement in space (symmetrical, asymmetrical) and movement compounds in choreographic phrases.

During the second semester, students take on various creative tasks - they use space as a multidimensional environment for the movement deployment, acquire horizontal and vertical lines in space, changing focus and direction and other techniques related to the usage of space. At the end of the semester, as part of their independent work, students create a staging, the main task of which is to use different space acquisition techniques in dance composition. Demonstration of the independent work is followed by an analysis of the creative pieces, using the criteria developed by the teacher - logical evolution and dynamics of the drawing according to the chosen theme and music.

And during the third semester, students, while still at the associativelevel, take up tasks of a higher degree of difficulty - they learn to use spoken or sung texts and to incorporate objects in the dance composition; but the main lesson in this semester is to use repetition and canon in the structuring of dance movements. At this stage, it is important to rely on the evident and emotionally effective examples. Therefore, one of the examples students are shown is Birgit Cullberg's staging of the ballet Carmen (choreographer Mats Exam, Schedrin / Bizet's music), where it is possible to ascertain the efficiency of unison and canon use in the modern ballet. 
A very important source in the study process is methodological material elaborated by the US choreographer and teacher Cathy Roe, in which her lectures on the basic principles and qualities of dance composition are supplemented with relevant excerpts from ballets and dances. The teacher's task in this practice is to maintain interest in the creative process in various ways, to establish a dialogue with both the task's performer, as well as with other students in order to search for the best possible solutions. It is important to not only teach the students an understanding of the placement of the movement in space and time, but also to evaluate the quality of the solution.

During the fourth semester, students are considered to be at the autonomous level of the dance composition movement skill acquisition. Based on the knowledge and skills acquired during the previous semesters, students become acquainted with the rules of dance drama and create an independent work as a solo dance performance. To prepare for this important stage of cognition, the teacher introduces students to the major solo dance examples from Latvian and European culture. This includes an analysis of choreographies Diždancis (Great Dance), Raibie Cimdi (Colorful Gloves) and Novadnieki (Regional Dance) by Uldis Zagata (Žagata), classical ballet variations, the latest television show productions, a discussion on the creative work principles of the choreographer Leonid Yakobson. Students look for solutions to one of the most complicated tasks in dance composition - creation of a conflict and its resolution in motion.

In order to accomplish this task, students must be able to use high-level movement skills associated with new, unusual solutions. In theory, researchers Krasnov and Wilmerding solve this problem, stressing that within the study process, it is important to be aware of closed and open skill formation. The term "closed skills" implies movements that are learned by accurate acquisition and imitation like a ballet pirouette or any other movement, which requires the initial state and the final movement closure.

Such a motion acquisition requires regular training and time from the performer. The aim of the "closed skills' is the accuracy of execution, and it is focused primarily on the concentration of power. By contrast, 'open skills' are related to the operational variativity and movement diversification in time and space. At this development stage, strong movement fixation is contrasted by the diversification principle, which facilitates the diversity and variativity of the movement.

While getting to know the principle of diversification, students form an understanding of movement building at different tempos and rhythmic structures, as well as in a variety of dance styles and genres. As Krasnov and Wilmerding state, conscious development and further use of closed and open skills is an important factor to reaching successful study outcomes (Krasnov, Wilmerding, 2015).

To purposefully refine motor skills in the Dance Composition study subject, it is appropriate to introduce the Fitts/Posner model, which provides a targeted strengthening and development of movement skills, taking into account each student's personal experience and progress. The advantage of the model is revealed through the interest that students show, cognitive activity and high artistic indicators.

\section{Conclusions}

Research results show that successful acquisition of the dance composition study subject manifests itself through the condition that it is based on certain dance skills (folk dance, modern dance, sports dance, etc) and student's somatic skills. However, successful use of the Fitts/Posner three-level learning model in the study process provides a transition from the lower level to highest level dance composition skills. This path is individual and depends mainly on students' cognitive activity, which largely is maintained by the educator, choosing appropriate pedagogical methods and techniques for each skill level. Research results reveal that the ability to transfer acquired movement skills to new situations and to use them in independent creative tasks shows a high user level, which is the aim of the introduction of the proposed model. The importance of the results manifests in the fact that the introduction of the three-level training model is one of the most preferred approaches to dance composition skill development during the study process. The article analyses the effectiveness of the proposed model in the implementation of the Dance Composition study course at Riga Teacher Training and Educational Management Academy, the indicators of which are evidence of pedagogical observation and analysis of performance - students' high level of 
interest in the study programme during the acquisition, increased cognitive activity, students' ability to perform movement diversification in complex artistic challenges, etc. However, the efficiency of the model is also confirmed by its impact on the programme graduates, who in their own working life after graduation are able to continue developing movement skills, create dance performances for dancers of different generations and dance genres, and take part in creative competitions and receive awards for successful creative work. Sustainability and quality of their practice is one of the most convincing arguments for introducing the three-level learning model for the development of composition skills during the study process.

\section{References}

Adams, J.A. (1984). Historical Review and Appraisal of Research on the Learning, Retention, and Transfer of Human Motor Skills. Psychological Bulletin University of Illinois at Urbana-Champaign, Vol. 101, No. 1, pp.41-74.

Edwards William, H. (2011). Motor Learning and Control. WADSWORTH, Cengage Learning, pp. 57-59.

Fitts, P.M. \& Posner, M. I. H.(1967). Human Performance. Belmont, CA: Brooks/Cole.

Krasnov, D.H., Wilmerding, M.V.(2015). Motor Learning and Control for Dance. Human Kinetics.

Magill, R.A. (2007). Motor Learning and Control: Concepts and Applications. 8th ed. New Your, NY: McGraw-Hill.

Spalva, R. (2004). Tēls un dejas kompozīcija. [Image and Dance Composition]. Rīga:Raka, 64.lpp.

Spalva,R.(2014). Dejas kompozīijas prasmju attīstība studentu mākslinieciskajā darbībā. [Development of Dance

Composition Skills in Student Artistic Activities]. GlobeEdit, OmniScriptum, GmbH\&Co.

Мерло-Понти М. (1999). Феноменология восприятия [Phenomenology of Perception]. Санкт-Петербург: Наука. Encyclopedia Britannica, http://www.britannica.com/art/choreography). 